\title{
Cholinergic Modulation of Activity-Dependent Synaptic Plasticity in the Piriform Cortex and Associative Memory Function in a Network Biophysical Simulation
}

\author{
Michael E. Hasselmo and Edi Barkai \\ Department of Psychology and Program in Neurosciences, Harvard University, Cambridge, Massachusetts 02138
}

The effect of activation of cholinergic receptors on longterm potentiation (LTP) in rat piriform cortex pyramidal cells was studied using extracellular and intracellular recordings in brain slice preparations. The functional role of this modulation was studied in a realistic network biophysical simulation.

Repetitive stimuli were applied in two paradigms: one in which the recorded cell was held at its resting potential and one in which synaptic activity was superimposed on a depolarizing pulse strong enough to evoke four action potentials. In the absence of cholinergic modulation, stimulation at $5 \mathrm{~Hz}$ induced LTP primarily in the second condition (13.7\%, $n=6$ out of 9 , measured at 10 min after tetanus). When stimuli were applied in the presence of the muscarinic agonist carbachol $(20 \mu \mathrm{M})$, LTP of greater amplitude was induced in both paradigms (resting: $41.5 \%, n=11$ out of 16 , depolarized: $36 \%, n=5$ out of 7 , measured at $10 \mathrm{~min}$ after tetanus). Increases in excitatory postsynaptic potential (EPSP) amplitudes in the presence of carbachol were gradual, starting at the time $5 \mathrm{~Hz}$ stimuli were applied and continuing until an action potential was evoked synaptically. In the presence of the NMDA receptor antagonist 2-amino-5-phosphonovaleric acid (APV), LTP could not be induced. The muscarinic antagonist atropine also prevented LTP induction in the presence of carbachol.

Cholinergic modulation of synaptic plasticity was examined in a previously developed realistic biophysical network simulation. In simulations, use of a gradual rate of synaptic modification prevented excessive strengthening of synapses, which could cause interference between stored patterns. The effect of excess synaptic strengthening can be avoided by introducing activity dependent depression of synaptic strength. Coactivation of learning and depression rules results in a stable system where no interference occurs, at any rate of learning. Implementing the depression rule only during recall does not improve the network's performance. This implies that reduction in the

\footnotetext{
Received Dec. 14, 1994; revised Apr. 27, 1995; accepted May 8, 1995.

This work was supported by an Office of Naval Rescarch Young Investigator Award to M. Hasselmo (N00014-93-1-595), a pilot grant from the Massachusetts Alzheimer Disease Research Center, and NIMH Award R29 MH5273201. We thank M. Wilson and J. M. Bower for access to previous models of piriform cortex, G. Horwitz and R. Bergman for current programming, and the GENESIS development team of J. M. Bower, M. Wilson, U. Bhalla, D. Beeman, M. Vanier, J. Uhley, D. Bilitch, and E. DeSchutter.

Correspondence should be addressed to Edi Barkai, Department of Physiology, Faculty of Health Sciences, Ben-Gurion University of the Negev, Beersheva 84105 , Israel.

Copyright (c) 1995 Society for Neuroscience $0270-6474 / 95 / 156592-13 \$ 05.00 / 0$
}

strength of synaptic connections should occur in the presence of $\mathrm{ACh}$, more than in normal conditions.

We propose that two effects of $\mathrm{ACh}$-enhancement of LTP and enhancement of LTD-should act together to increase the stability of the cortical network in the process of acquiring information.

[Key words: muscarinic, potentiation, depression, brain slice, GENESIS]

Long term potentiation is a form of long lasting enhancement of the amplitude of synaptic potentials that follows repetitive activation of a defined pathway. It has been demonstrated and studied most extensively in the hippocampus (for review, see Bliss and Collingridge, 1993; Hawkins et al., 1993), but has also been described in the neocortex (Artola and Singer, 1987; Bear et al., 1992; Brocher et al., 1992) and piriform cortex (Jung et al., 1990; Kanter and Haberly, 1990, 1993). In the piriform cortex, high frequency bursts applied at the theta frequency induce long-term potentiation which depends upon the activation of NMDA channels (Jung et al., 1990; Kanter and Haberly, 1990, 1993).

Acetylcholine ( $\mathrm{ACh}$ ) has been demonstrated to enhance the induction of LTP in hippocampal region CA1 (Hirotsu et al., 1989; Blitzer et al., 1990; Tanaka et al., 1989; Huerta and Lisman, 1994) and in the dentate gyrus (Burgard and Sarvey, 1989). This may be related to the cholinergic enhancement of stimulation-initiated protein synthesis via an NMDA-dependent mechanism (Feig and Lipton, 1993) and to cholinergic potentiation of NMDA receptor mediated responses (Markram and Segal, 1990). The cholinergic enhancement of synaptic modification has been assumed to play an important role in the storage of information in cortical structures, but the effect of this enhancement on the dynamics of network function has not been analyzed in computational models.

Blockade of muscarinic cholinergic receptors has been shown to impair learning of new information in a wide range of behavioral tasks (Sutherland ct al., 1982; Hagan et al., 1987; Aigner et al., 1991; Hasselmo, 1995). In particular, antagonists such as scopolamine impair the learning of new odors in a test of odor recognition (Soffie and Lamberty, 1988; Hunter and Murray, 1989). However, it is not clear how these behavioral effects relate to the physiological effects of acetylcholine within structures such as the piriform cortex. Within the piriform cortex, several physiological effects of $\Lambda \mathrm{Ch}$ have been demonstrated. Cholinergic agonists cause selective suppression of intrinsic but not afferent fiber synaptic transmission (Hasselmo and Bower, 1992, 1993), suppression of the adaptation of firing frequency 


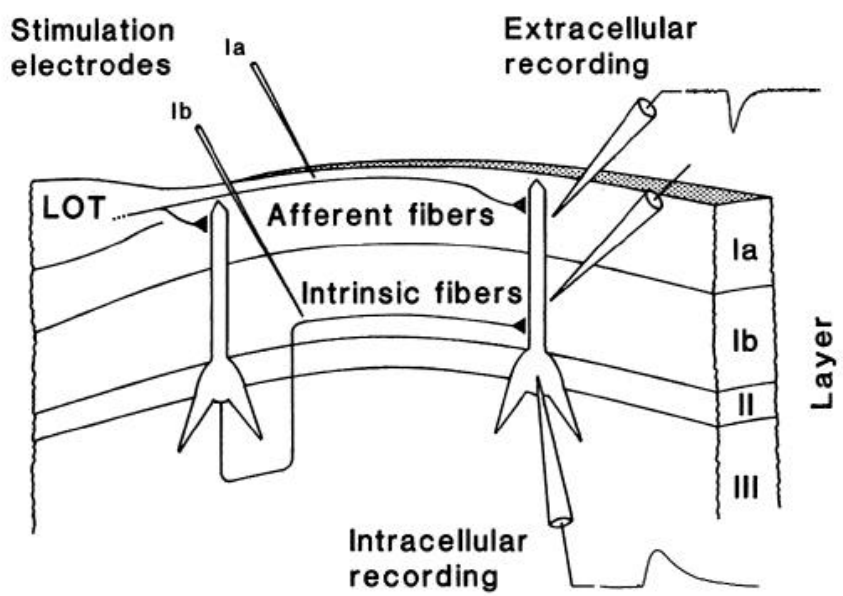

Figure 1. A schematic representation of the piriform cortex slice preparation. Pyramidal cells receive excitatory afferent input in the distal dendrite from olfactory bulb afferent fibers and excitatory intrinsic input in the proximal dendrite from other cortical pyramidal cells. Stimulating electrodes were placed in layer Ib (intrinsic fiber layer). Extracellular recordings were performed in layer $\mathrm{Ib}$ and intracellular recordings from pyramidal cell bodies located in layer II.

in pyramidal cells in layer III (Tseng and Haberly, 1989) and layer II (Barkai and Hasselmo, 1994, Barkai et al., 1994). Previous modeling work has shown how these effects of ACh may set the proper dynamics for learning in the piriform cortex (Hasselmo et al., 1992; Hasselmo, 1993, 1994; Hasselmo et al., 1994; Barkai et al., 1994). However, the enhancement of learning in these models required cholinergic enhancement of synaptic modification in the piriform cortex similar to that seen in the hippocampus. Here we provide experimental evidence for this cholinergic enhancement of synaptic modification, and explore how details of the cholinergic modulation of synaptic modification affect the dynamics of network function.

\section{Materials and Methods}

\section{Brain slice experiments}

Experiments were performed on brains removed from etherized female albino Sprague-Dawley rats 4-6 weeks of age. Slices of piriform cortex were prepared and maintained following standard procedures (Barkai and Hasselmo, 1994) in accordance with institutional guidelines. Slices were cut perpendicular to the laminar organization of piriform cortex in the coronal plane, with a thickness of $400 \mu \mathrm{m}$, and maintained in a solution with the following ionic concentrations: $\mathrm{NaHCO}_{3} 26 \mathrm{~mm}, \mathrm{NaCl}$ $124 \mathrm{~mm}, \mathrm{KCl} 5 \mathrm{~mm}, \mathrm{KH}_{2} \mathrm{PO}_{4} 1.2 \mathrm{~mm}, \mathrm{CaCl}_{2} 2.4 \mathrm{~mm}, \mathrm{MgSO}_{4} 1.3 \mathrm{~mm}$, and glucose $10 \mathrm{~mm}$. For recording, slices were mounted on a nylon grid in a standard submersion-type slice chamber, with temperature maintained at $37^{\circ} \mathrm{C}$. Slices were transilluminated, which allowed visually guided placement of stimulating and recording electrodes in layer Ib, the intrinsic fiber layer, as shown in Figure 1. Extracellular recordings were made in layer Ib using $2 \mathrm{M} \mathrm{NaCl}$ electrodes with impedance of 2-4 M $\Omega$ (Hasselmo and Bower, 1991, 1992; Tang and Hasselmo, 1994). Intracellular recordings were made from the cell bodies of layer II pyramidal cells (Barkai and Hasselmo 1994) using 4 м potassium acetate electrodes with impedances from 50 to $100 \mathrm{M} \Omega$. Cells were only studied if they had a stable resting membrane potential at or below $-65 \mathrm{mV}$ and a spike amplitude of at least $85 \mathrm{mV}$.

Effects on the amplitude of synaptic transmission were analyzed by measurement of the height of synaptic potentials elicited by layer Ib stimulation presented at $0.1 \mathrm{~Hz}$ (once every $10 \mathrm{sec}$ ). The maximal deviation from baseline potential was measured on synaptic potentials elicited before and after repetitive stimulation trains presented to this layer for induction of LTP. In experiments testing the induction of LTP, 50 single stimuli were applied at a rate of $5 \mathrm{~Hz}$. A neuron was classified as demonstrating long-term potentiation if it showed a change in height of the synaptic potential greater than $5 \%$ of the baseline height. In some cases during intracellular recording, this stimulation was presented in conjunction with intracellular current injection sufficient to elicit four action potentials in the postsynaptic neuron, following the protocol used to test Hebbian synaptic modification in the hippocampus (Wigstrom et al., 1986).

For analysis of the effects of cholinergic modulation, the cholinergic agonist carbachol (carbamylcholine chloride) was delivered through the medium bathing the slices in the recording chamber at a concentration of $20 \mu \mathrm{M}$. This concentration was chosen on the basis of previous voltage-clamp studies showing strong suppression of both voltage and calcium-dependent potassium currents at this concentration (Constanti and Sim, 1987; Madison et al., 1987). 2-Amino-5-phosophonovaleric acid (APV) $(50 \mu \mathrm{M})$ and atropine $(10 \mu \mathrm{M})$ were also applied through the bathing medium. Pharmacological agents were present continuously before, during, and after repetitive stimulation.

\section{Computational simulations}

Single cell modeling. Simulations of the enhancement of synaptic modification utilized computational models of single neurons and network interactions described extensively in two recent papers from this laboratory (Barkai and Hasselmo, 1994; Barkai et al., 1994). Intracellular records of pyramidal cell firing properties were replicated in a biophysical simulation of a single piriform cortex pyramidal cell (Barkai and Hasselmo, 1994), using the GENESIS simulation package (Wilson and Bower 1989, 1992). Cholinergic effects on synaptic transmission, neuronal adaptation and synaptic modification were included in the model, as summarized in Figure 2. Development of the network model of associative memory function in the piriform cortex was based upon earlier biophysical simulations of the piriform cortex (Wilson and Bower, 1988, 1992), and earlier theoretical descriptions of the possible role of the piriform cortex as an associative memory (Haberly, 1985; Wilson and Bower, 1988; Haberly and Bower, 1989).

In order to maintain flexibility for incorporation of the single neuron simulations into a large network biophysical simulation containing 240 neurons, the number of compartments in the pyramidal cell simulation was restricted to three: a distal dendritic compartment, a proximal dendritic compartment, and a somatic compartment, as shown in Figure $2 \mathrm{~A}$. The dendritic compartments were $100 \mu \mathrm{m}$ in length and $2.5 \mu \mathrm{m}$ in diameter, while the somatic compartment was $12 \mu \mathrm{m}$ in length and 20 $\mu \mathrm{m}$ in diameter. The temporal and spatial dynamics of fluctuations in membrane potential due to membrane currents were approximated based on an equivalent circuit model of the membrane. These compartmental simulations show the nonlinear characteristics of temporal and spatial summation similar to cortical neurons. The neuronal membrane parameters were $R_{m}=4.0 \times 10^{9} \mathrm{~K} \Omega-\mu \mathrm{m}^{2}$ and $C_{m}=1.0 \times$ $10^{-8} \mu F / \mu \mathrm{m}^{2}$, while $R_{a}=500 \mathrm{~K} \Omega-\mu \mathrm{m}$. When the presence of ACh was simulated, $R_{m}$ was increased to $1.5 \times 10^{10} \mathrm{~K} \Omega-\mu \mathrm{m}^{2}$, as a representation of the experimentally observed effect of cholinergic agonists on input resistance (Barkai and Hasselmo, 1994).

The pyramidal cell simulations contained a range of synaptic and voltage-dependent conductances as shown in Figure $2 A$, which influenced the membrane potential via changes in the conductances within the equivalent circuit model. Changes in different ionic conductances altered the relative contribution to the membrane potential of the Nernst potentials for different ions, including sodium $\left(E_{\mathrm{Na}}=+55 \mathrm{mV}\right)$, potassium $\left(E_{\mathrm{K}}=-90 \mathrm{mV}\right)$, chloride $\left(E_{\mathrm{Cl}}=-65 \mathrm{mV}\right)$ and calcium $\left(E_{\mathrm{Ca}}=\right.$ $90 \mathrm{mV})$. Voltage-dependent channels influencing these conductances were modeled using the standard Hodgkin-Huxley framework. Generation of action potentials in simulated neurons depended upon the fast voltage-dependent sodium current $\left(I_{\mathrm{Na}}\right)$ and the delayed rectifier potassium current $\left(I_{\mathrm{K}(\mathrm{DR})}\right)$, with parameters provided in a previous publication (Barkai and Hasselmo, 1994). In addition to these currents, simulations incorporated two additional voltage-dependent potassium currents $\left(I_{\mathrm{K}(\mathrm{A})}\right)$ and $\left(I_{\mathrm{K}(\mathrm{M})}\right)$ and a calcium-dependent potassium current $\left(I_{\mathrm{K}(\mathrm{AHP})}\right)$. The simulation also included a high-threshold voltage-dependent calcium current $\left(I_{\mathrm{Ca}}\right)$ and a representation of the changing calcium concentration produced by the calcium currents. The equivalent circuit equation took the form

$$
\begin{aligned}
\frac{d V_{m}}{d t}=\{ & \left(E_{\text {leak }}-V_{m}\right) / R_{m i}+g_{\mathrm{Na}}\left(E_{\mathrm{Na}}-V_{m}\right)+g_{\mathrm{Cl}}\left(E_{\mathrm{Cl}}-V_{m}\right) \\
& +\left(g_{\mathrm{K}(\mathrm{DR})}+g_{\mathrm{K}(\mathrm{A})}+g_{\mathrm{K}(\mathrm{M})}+g_{\mathrm{K}(\mathrm{AHP})}\right)\left(E_{\mathrm{K}}-V_{m}\right) \\
& \left.+\sum_{x}\left(V_{m(x)}-V_{m}\right) / R_{a}+I_{\mathrm{in}}\right\} / C_{m},
\end{aligned}
$$




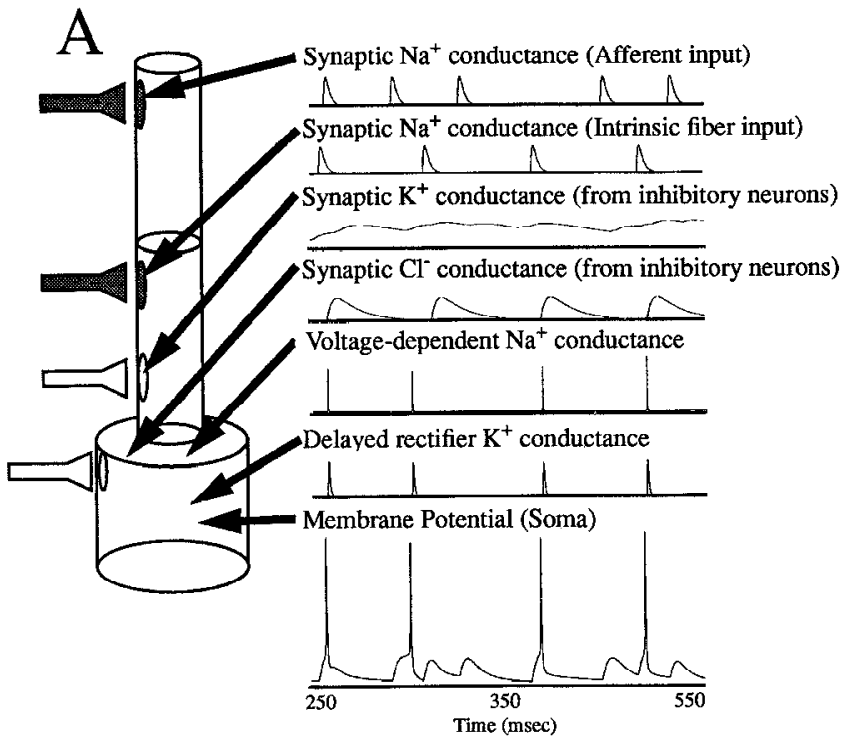

Enhancement of long-term potentiation

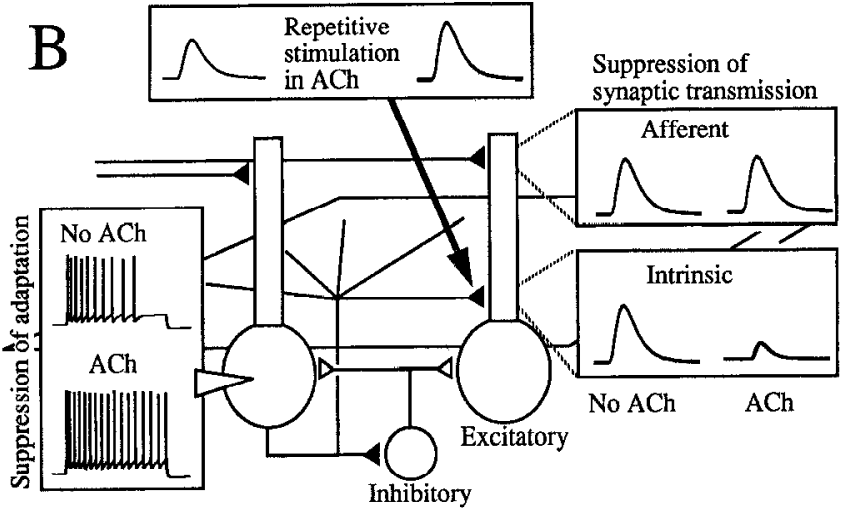

Figure 2. Schematic representation of the biophysical simulation. A, Biophysical simulation of a single piriform cortex pyramidal cell, with two dendritic and one somatic compartment containing a range of synaptic and voltage-dependent conductances. Synaptic conductances shown here include excitatory synaptic sodium conductances in the distal and proximal dendritic compartments, inhibitory potassium conductance in the proximal dendritic compartment and chloride conductance in the soma. Voltage-dependent conductances inclue the Hodgkin-Huxley fast sodium and delayed rectifier potassium conductances, which underlie the generation of action potentials in the membrane potential trace. Not shown: additional calcium and voltage-dependent potassium currents underlying adaptation. (Based on figure in Barkai et al., 1994). $B$, Single cell simulations were combined in a network biophysical simulation with 240 pyramidal cells and 58 each of two types of inhibitory interneurons activating potassium and chloride currents. The figure shows excitatory afferent and intrinsic fibers contacting the distal and proximal dendritic compartments of pyramidal cells, as well as a connection from a pyramidal cell to a fecdback inhibitory interncuron. Connectivity between pyramidal cells was broadly distributed (with $70 \%$ connectivity), while synapses arising from interneurons terminated more locally. A range of cholinergic effects were implemented during learning, including the enhancement of long-term potentiation (top), the suppression of neuronal adaptation (left), and the suppression of synaptic transmission (right).

where $V_{m}$ represents membrane potential, Nernst potentials for individual ions are represented by $E$ (for example, the sodium Nernst potential $=E_{\mathrm{N} a}$ ), ionic conductances of different types are represented by $g$ (for example, the calcium-dependent potassium conductance $\left.=g_{\mathrm{K}(\mathrm{AHP})}\right) . C_{m}$ $=$ the membrane capacitance, and $R_{m}=$ membrane resistance. For further details of single cell simulations, see Barkai and Hasselmo (1994).

Network modeling. As shown in Figure $2 B$, a network biophysical simulation of associative memory function in the piriform cortex was constructed by combining 240 of the biophysical simulations of pyramidal cells described in the previous section, along with 58 cach of two types of inhibitory interneuron. Action potentials generated in individual neurons induced synaptic potentials with a dual exponential time course in other neurons after a transmission delay. These transmission delays were calculated based on the distance between modeled neurons and the experimentally derived transmission delays along those axons, as developed in extensive previous biophysical simulations of piriform cortex (Wilson and Bower, 1988, 1989, 1992). The smaller size of the network relative to the size of the piriform cortex required increases in the maximal strength of the synaptic conductance at individual synapses (Wilson and Bower, 1989), in order to maintain realistic levels of neuronal activity within the model. In the present study, the strongest syn aptic weight was 180 times stronger than the minimal possible weight. In addition, associative memory function in these smaller networks required higher percent connectivity than in the actual cortex. The simulations presented here utilized $70 \%$ synaptic connectivity. In this simulation, cells providing afferent input were not represented as compartmental simulations. Instead, input patterns simply represented the pattern of activity on afferent fibers entering the piriform cortex from the mitral and tufted cells of the olfactory bulb. Each afferent fiber was active or inactive dependent upon the particular input pattern and was connected to $5 \%$ of the pyramidal cells on average.

Synaptic currents were represented by shifts in ionic conductances to $\mathrm{Na}^{+}$for excitatory afferent and intrinsic synapses and $\mathrm{Cl}^{-}$and $\mathrm{K}^{+}$respectively for $\mathrm{GABA}_{\mathrm{A}}$ and $\mathrm{GABA}_{\mathrm{B}}$ inhibitory synapses. The synaptic currents induced by the arrival of presynaptic spikes were summed at each synapse. Simulations of the time course of synaptic currents induced by each presynaptic spike arrival followed a standard dual exponential time course with time constants dependent upon the specific receptor and channel type (Wilson and Bower, 1989), representing the response to a single brief pulse of transmitter triggered by the spike. This time course took the form

$$
g(t)=w_{i j}(t) * g_{\text {peak }} *\left(\tau_{1} \tau_{2} /\left(\tau_{2}-\tau_{1}\right)\right)\left(e^{-t / \tau_{2}}-e^{-t / \tau}\right),
$$

where $w_{\mathrm{ij}}$ represents the strength of the synapse from neuron $\mathrm{j}$ to neuron $i, g_{\text {peak }}$ is the maximum conductance of each channel, $\tau_{1}$ is the rise time and $\tau_{2}$ is the decay time of the synaptic potential. Time constants were chosen to accurately incorporate the experimental evidence for a more rapid time course of excitatory glutamatergic synaptic transmission and $\mathrm{GABA}_{\mathrm{A}}$ inhibition, versus a longer, slower time course for $\mathrm{GABA}_{B}$ inhibition (Connors et al., 1988; Tseng and Haberly, 1988). Details of the time constants and synaptic delays for the synaptic potentials utilized in network simulations are presented in a previous publication (Barkai et al., 1994).

Two states of the network: learning mode and recall mode. The effect of cholinergic modulation on associative memory function was tested by applying cholinergic modulation during the storage of five different patterns of activity, and then removing the cholinergic modulation during testing of the recall of the network. In this network two modes were simulated: a learning mode and a recall mode. In learning mode, effects that occur in the presence of $\mathrm{ACh}$ were simulated; synaptic activity in the intrinsic fibers was suppressed, neuronal adaptation was decreased, and the strength of connections between neurons that were firing simultaneously was increased. These effects are illustrated in Figure $2 B$. In the recall mode, the effects of $\mathrm{ACh}$ were eliminated and the capability of the network to perform associative memory function was tested by its ability to complete a degraded version of a pattern which was presented in full during learning. In quantitative tests, cholinergic suppression of neuronal adaptation was represented by changing the parameters of the $I_{\mathrm{K}(\mathrm{M})}$ and $I_{\mathrm{K}(\mathrm{AHP})}$ (see Barkai and Hasselmo, 1994) and the suppression of intrinsic fiber synaptic transmission was represented by reducing the maximal conductance of postsynaptic sodium currents in the proximal dendritic compartment by $70 \%$ (see Barkai et al., 1994).

In keeping with the findings described in the Results section of this article, learning in the biophysical network simulation depended on strengthening of intrinsic excitatory synapses according to a Hebb-type learning rule. During learning, the synaptic weight parameter $w_{\mathrm{ij}}$ for the synapse from neuron $j$ to neuron $i$ was increased in proportion to preand postsynaptic activity, according to the learning rule:

$$
\Delta w_{i j}=\left(\eta * f\left(\left\langle V_{m}(t)_{i}\right\rangle-\Omega\right)-\gamma * w_{i j}\right) * h\left(V_{m}\left(t-\delta_{i j}\right)_{j}-\theta\right)
$$

Synaptic modification occurred when an action potential in neuron $j$ reached the presynaptic terminal for the synapse with neuron $i$. When the presynaptic voltage $V_{m}$ passed the spike detection threshold $\theta$ (set 


\section{control}

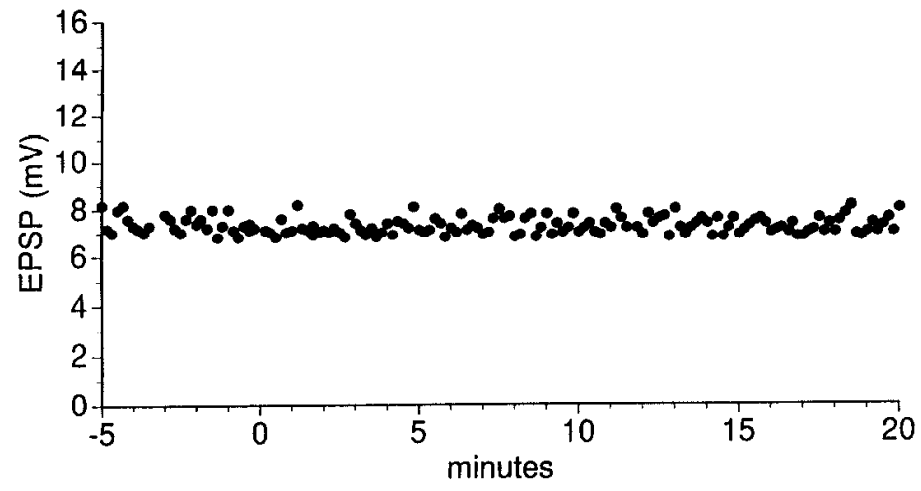

before

20 min after

superimposed
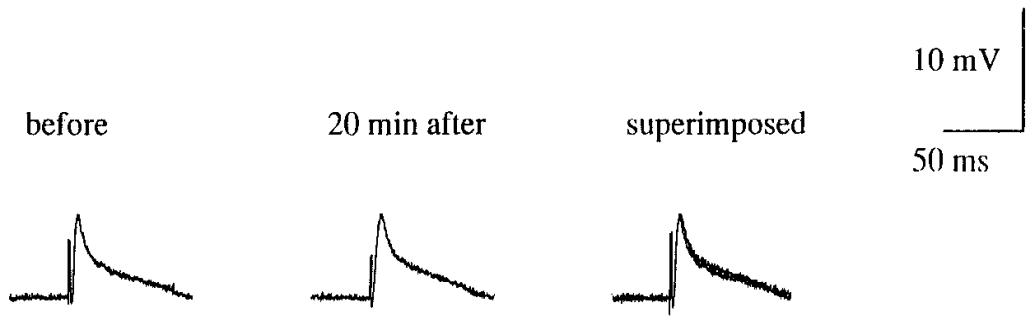

Figure 3. Effect of repetitive stimulation in control slices. Fifty stimuli given at $5 \mathrm{~Hz}$ did not induce changes in the height of synaptic potentials in control conditions. Top, The height of synaptic potentials evoked in a pyramidal cell by $0.1 \mathrm{~Hz}$ stimulation of layer Ib is shown beginning $5 \mathrm{~min}$ before and ending $20 \mathrm{~min}$ after the $5 \mathrm{~Hz}$ stimulation. Bottom, Averages of intracellular synaptic potentials are shown for this individual neuron before and 20 minutes after the 50 stimuli presented at $5 \mathrm{~Hz} . R_{\mathrm{in}}=21 \mathrm{~m} \Omega, V_{m}=-72 \mathrm{mV}$.

at $-30 \mathrm{mV}$ ), the spike was represented at the presynaptic terminal after a transmission delay $\delta_{i j}$, and the function $h()$ took a value of 1 for the presence of a spike, and 0 for the absence of a spike. This presynaptic spike detection was multiplied by the postsynaptic membrane potential $V_{m}$ averaged over a 20 msec interval preceding the arrival of the spike (represented by \langle\rangle ). This is meant to approximate the dual influence of glutamate binding and postsynaptic depolarization on the NMDA receptor currents assumed to underlie synaptic modification. However, glutamate can remain bound to the NMDA receptor for long periods, which could allow the activity of the receptor to be influenced by postsynaptic potential during a time period following rather than preceding the arrival of a presynaptic spike. These differences in timing are shortterm relative to the extended depolarization resulting from repetitive activation of neurons in this model. Therefore, this feature does not qualitatively influence the associative memory function of the network. The function $f()$ was threshold linear, taking zero value below the modification threshold $\Omega$ (set at $-64 \mathrm{mV}$ ), and increasing linearly above the threshold. The rate of change of synaptic strength was determined by the learning gain $\eta$. The depression of synaptic strength was proportional to the current strength of the synapse, and to a depression constant $\gamma$. Similar to the strengthening, this depression only occurred when presynaptic activity was present, as a representation of the activity dependence of homosynaptic depression (Levy et al., 1990).

Using the parameters chosen for this study, when the learning gain was set to 30 nearly all "active synapses" reached the maximal possible weight $(180)$. Therefore, learning gain of 30 was referred to as "normalized learning rate 1.0 ," learning gain of 15 was referred to as "normalized learning rate of 0.5 " and so on. Synaptic enhancement was terminated when synapses reached a maximal strength $W_{\max }$. The depression parameter $\gamma$ determined the ratc of depression. When the de pression rate was 1.0 , this caused complete depression of the synaptic strength on a single learning step (in the absence of synaptic strengthening). Synaptic depression was terminated when synapses reached a minimum strength $W_{\min }$. Note that in most cases, synaptic enhancement and depression were implemented only during cholinergic modulation.

Testing associative memory function. Each afferent pattern activated two afferent fibers, resulting in broadly distributed activity in the piriform cortex due to the broad divergence of afferent connectivity. Five different input patterns were presented. The input patterns did not overlap in the afferent fibers, but since connectivity between afferent fibers and pyramidal cells was random, overlap between patterns was very likely and was indeed evident when the activity of the cortical network was examined. The recall of the network was tested by presenting degraded versions of these five patterns which activated only one input line each, therefore directly stimulating only about $50 \%$ of the pyramidal cells normally activated by the full pattern.
The effectiveness of recall was quantified using a performance measure previously used to test associative memory function (Hasselmo et al., 1992; Barkai et al., 1994, Hasselmo, 1994). This performance measure was based on normalized dot products computed between two vectors: one vector consisted of the spiking response of each neuron to the degraded pattern and the other vector consisted of the spiking response of each neuron to the full version of that same pattern. Each spiking response vector contained 240 clements consisting of the number of action potentials fired by each pyramidal cell in response to a pattern during a $500 \mathrm{msec}$ period. The normalized dot product is equivalent to the cosine of the angle between the vectors described by the spiking response of the 240 pyramidal cells to each input pattern and is a standard performance measure used in more abstract neural network models (Kohonen, 1988; Hasselmo et al., 1992).

This normalized dot product was incorporated in a performance measure which computed the amount of overlap between the patterns of cortical activity relative to the actual overlap between the full and degraded input patterns. This "normalized performance measure" gives a measure of how much the network improves the recall of the pattern relative to its level of degradation, and has been used as part of a more complex performance measure from previous simulations (Hasselmo et al., 1992; Hasselmo, 1994). When the normalized dot product between the spiking responses to the degraded and full patterns was exactly proportional to the dot product between the degraded and full input patterns, the performance measure took a value of zero. When the spiking response to degraded patterns matched the spiking response to full patterns more closely than the degraded input matched the full input pattern, the performance measure took nonzero values. Thus, the performance measure increased with improved memory performance.

\section{Results}

\section{LTP induction in the presence of carbachol}

In control solution, stimulation at $5 \mathrm{~Hz}$ for $10 \mathrm{sec}$ (a total of 50 stimuli) did not result in enhancement of the amplitude of EPSPs when there was no current injection during stimulation. No significant potentiation was observed during intracellular recording from eight neurons, with an example shown in Figure 3 . When the postsynaptic neuron was depolarized with a current sufficient for evoking four action potentials concurrent with the presynaptic stimulation of synaptic input, LTP was induced in 6 out of the 9 cells recorded. However, in these 6 cells the potentiation was small, with an average of $13.7 \%$ (recorded $10 \mathrm{~min}$ after tetanus). This change in amplitude of synaptic potentials was 


\section{$20 \mathrm{uM}$ carbachol}

Figure 4. Carbachol enables the induction of long-term potentiation (LTP); $5 \mathrm{~Hz}$ repetitive stimulation induces long lasting changes in the height of intracellulary recorded synaptic potentials in the presence of 20 $\mu \mathrm{M}$ carbachol. Top, The height of synaptic potentials evoked in a pyramidal cell by stimulating layer $\mathrm{Ib}$ was measured at $0.1 \mathrm{~Hz}$. The plot shows measurements beginning $5 \mathrm{~min}$ before and ending $20 \mathrm{~min}$ after repetitive $5 \mathrm{~Hz}$ stimulation. The increase in synaptic potential amplitude was gradual, beginning after repetitive stimulation. Bottom, Averages of intracellular synaptic potentials before and $20 \mathrm{~min}$ after presentation of 50 stimuli at $5 \mathrm{~Hz}$ in the presence of carbachol. $R_{\text {in }}=23 \mathrm{~m} \Omega, V_{m}$ $=-73 \mathrm{mV}$.

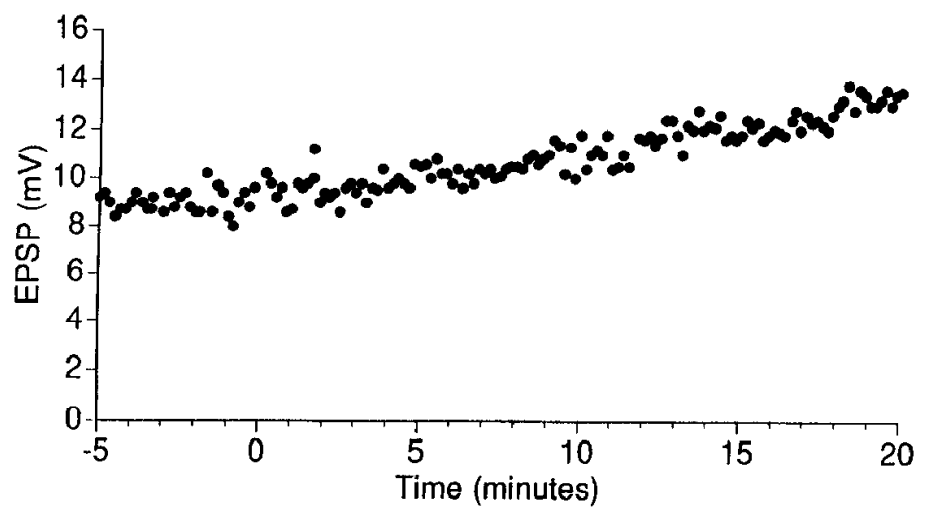

before

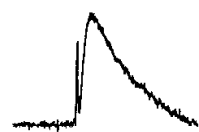

20 min after

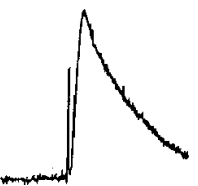

superimposed

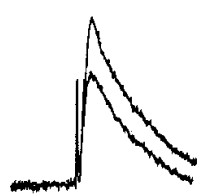

$50 \mathrm{~ms}$ observed after the repetitive stimuli were delivered and showed little change in amplitude thereafter.

When the muscarinic agonist carbachol $(20 \mu \mathrm{M})$ was present in the perfusing medium, the same stimuli evoked a gradual increase in the amplitude of EPSPs. (Note that carbachol was present during the full duration of the experiment). This change started at the end of repetitive stimulation and usually continued for as long as the recording lasted during extracellular recording, or until an action potential was evoked by the synaptic stimuli when recording was intracellular, in which case the height of synaptic potentials in response to that stimulus strength was no longer measurable. The response did not decrease during the period of recording from the neuron (up to $2 \mathrm{hr}$ and $20 \mathrm{~min}$ ). No short term potentiation was observed in these conditions, probably due to the low stimulus frequency of repetitive stimulation. An example of the gradual increase in intracellularly recorded EPSP amplitude after repetitive stimulation is shown in Figure 4. Measured $10 \mathrm{~min}$ after the presentation of $5 \mathrm{~Hz}$ stimulation, potentiation was found in 17 out of 23 neurons recorded intracellularly in the presence of carbachol. In some experiments, the presynaptic stimulation was combined with intracellular current injection sufficient to evoke four action potentials. However, this did not result in a consistent difference in the rate or amplitude of change of the EPSPs. Neurons tested without injection of current during $5 \mathrm{~Hz}$ stimulation showed a $41.5 \%$ increase in height of potentials after $10 \mathrm{~min}(n=11$ out of 16). Neurons tested with injection of current during $5 \mathrm{~Hz}$ stimulation showed a $36 \%$ increase in height of potentials after $10 \min (n=5$ out of 7$)$.

A quantitative description of the rate of change in intracellularly recorded EPSP amplitude in the neurons is shown in Figure 5. This figure shows changes in EPSP amplitude up to 25 min after stimulation. At this point in time, previously subthreshold stimulation began to evoke an action potential in many of the intracellularly recorded neurons. Traces from a neuron in which the EPSP continued to increase up to $45 \mathrm{~min}$. after repetitive stimulation before evoking an action potential are shown in same figure. The muscarinic antagonist atropine prevented the enhancement of intracellularly recorded EPSPs following repetitive stimuli in the presence of carbachol (3/3, not shown). Recently, it has been demonstarated in the hippocampus that submicromolar doses of carbachol may induce a gradual increase in EPSPs, without any aditional stimulation. This effect was not noted in concentrations of carbachol greater than $5 \mu \mathrm{M}$ (Auerbach and Segal, 1994). Although some slight changes were observed in our experiments before the $5 \mathrm{~Hz}$ stimuli, these were much less prominent than the gradual increase observed after the stimulation. In four experiments, synaptic potentials were recorded intracellularly during $0.1 \mathrm{~Hz}$ stimulation in the presence of carbachol, showing no significant changes in height of potentials in response to this low frequency stimulation. Figure 6 illustrates the gradual change in extracellularly recorded synaptic field potentials after repetitive stimulation in the presence of $20 \mu \mathrm{M}$ carbachol. Potentiation was found in 4 out of 6 slices during extracellular recording, with an average of $42.3 \%$ tested at 20 min after tetanus. As seen in Figure 5, enhancement of the synaptic response began after the repctitive stimuli and continued until it reached an asymptotic value which remained stable throughout the recording.

Since it was previously suggested that $\mathrm{ACh}$ may enhance EPSPs in the hippocampus via enhanced activation of NMDA currents (Markram and Segal, 1990), we examined the effect of the NMDA blocker APV on the LTP enhanced by carbachol. Eight cells were tested in the presence of APV and carbachol. LTP was induced in these conditions only in one cell. A typical response is illustrated in Figure 7.

\section{Effect of learning rate on network performance}

The significance of the gradual increase in the amplitude of the EPSP in the presence of ACh was examined in a recently described realistic biophysical network simulation (Barkai et al., 1994; Hasselmo et al., 1994). The weights of intrinsic connections between pyramidal cells were increased as a function of their simultaneous activity, as described in the methods section. 


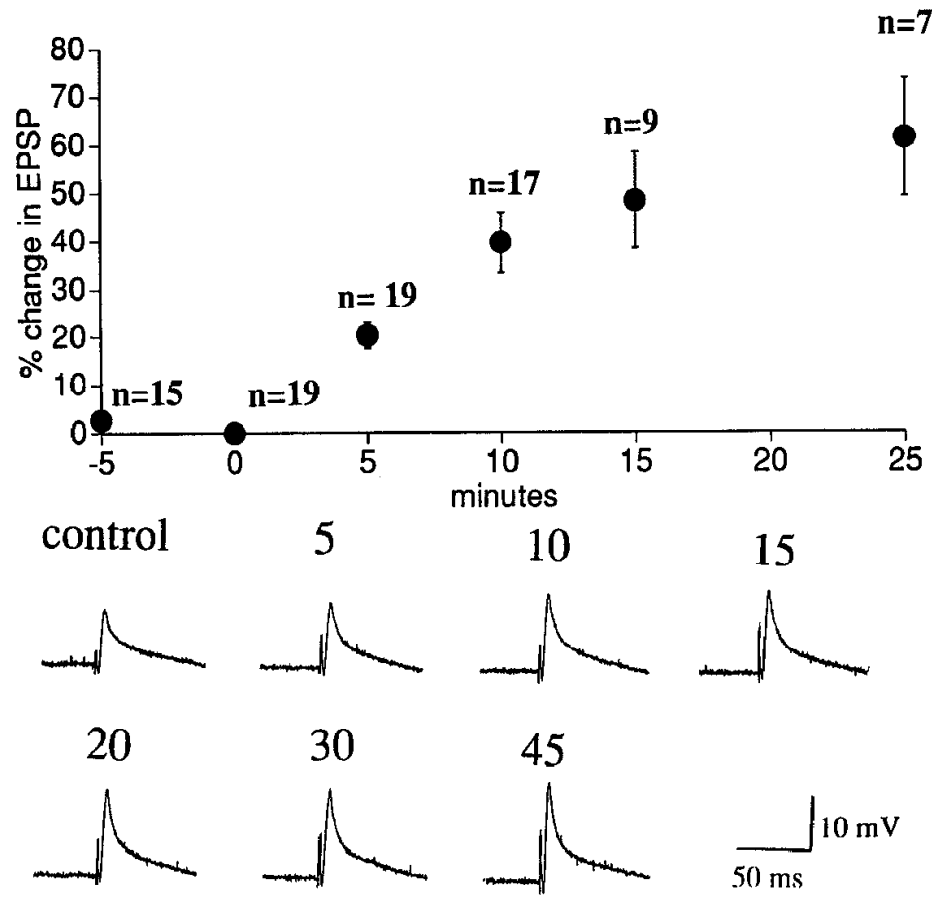

Figure 5. Quantitative description of the rate of change in intracellularly recorded synaptic potential amplitudes following repelitive stimulation. Percent change in height of EPSPs is shown as a function of time after repetitive stimulation is applied. Mean values $+\mathrm{SE}$ are indicated for intracellular recordings from a number of different neurons ( $n$ shown for each plot on graph). Lower traces demonstrate the gradual increase in amplitude recorded in a single neuron for up to 45 min after repetitive stimulation.

\section{0 uM carbachol}

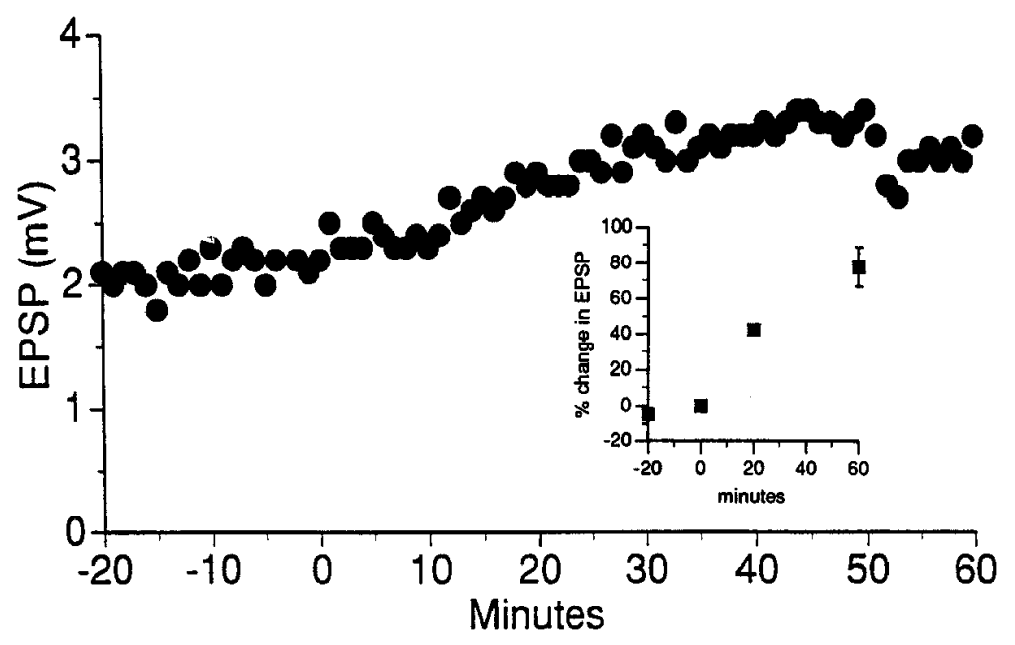

before stimuli

30 Min. after stimuli

superimposed

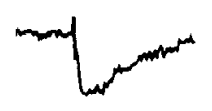

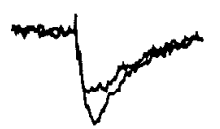

$3 \mathrm{MV}$
Figure 6. Example of LTP recorded extracellularly. The extracellular field potential gradually changes as result of repetitive $5 \mathrm{~Hz}$ stimuli in the presence of $20 \mu \mathrm{M}$ carbachol. After increasing for $30 \mathrm{~min}$ the potential stabilizes for the remaining period of the recording. The inset shows summarized results from the four slices that showed potentiation in the presence of carbachol (data shows average \pm SEM, $n=4$ for $-20,0$, and $40 \mathrm{~min}$ and 3 for $60 \mathrm{~min}$ ). Note that a small upward drift appeared even before the $5 \mathrm{IIz}$ stimulation, but significantly greater enhancement occurred after stimulation. 


\section{0 uM carbachol + 50 uM APV}

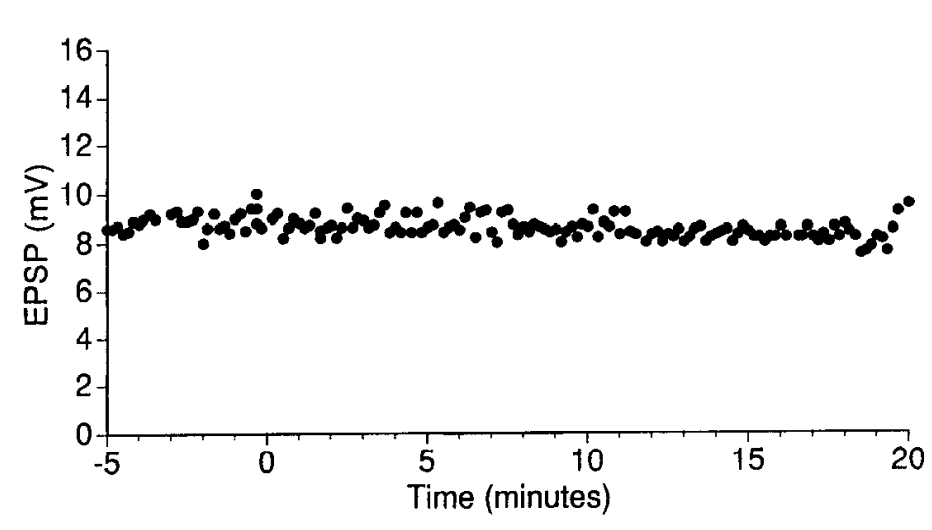

Figure 7. Induction of LTP is blocked by APV. The NMDA channel antagonist DL-APV $(50 \mu \mathrm{M})$ prevents the induction of LTP in the presence of carbachol. The height of synaptic potentials evoked in a pyramidal cell by $0.1 \mathrm{~Hz}$ stimulation of layer Ib was measured. The graph illustrates measurements beginning 5 min before and ending $20 \mathrm{~min}$ after repetitive stimulation. $R_{\text {in }}=18 \mathrm{~m} \Omega V_{m}=-73 \mathrm{mV}$.

before $20 \mathrm{~min}$ after superimposed

$50 \mathrm{~ms}$
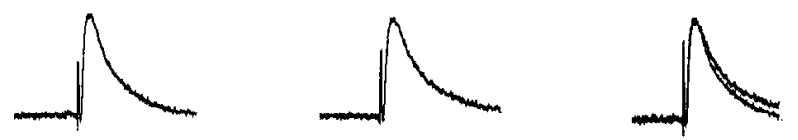

This gave the network the capacity to respond to degraded versions of stored input patterns with activity more closely resembling the response to the full learned pattern. An example of the associative memory function of the network biophysical simulation is shown in Figure 8 for one of the five patterns stored in this network. Note that learning can provide good recall of the stored pattern, but excessive strengthening of intrinsic synapses can lead to simultaneous recall of all stored patterns, resulting in a loss of discimination between patterns.

For analysis of the effects of cholinergic modulation of synaptic modification, five afferent input patterns were stored in the network. The final synaptic strength values in the synaptic connectivity matrix were a function of the five patterns presented and the rate in which changes in synaptic strength were allowed to occur. The ability of the network to store five partially overlapping patterns was clearly dependent on the rate in which synaptic changes were allowed to occur, as demonstrated in Figure 9. The first column shows the spiking response of the 240 pyramidal cells to each of the five patterns that activated the afferent fibers (size of black squares represents number of action potentials fired by an individual neuron). Since the connections between the afferent fibers and the pyramidal cells were determined randomly, this resulted in different amounts of overlap between the response to different afferent patterns.

As shown in Figure 9, different learning rates result in different final synaptic weight matrices. When a learning rate

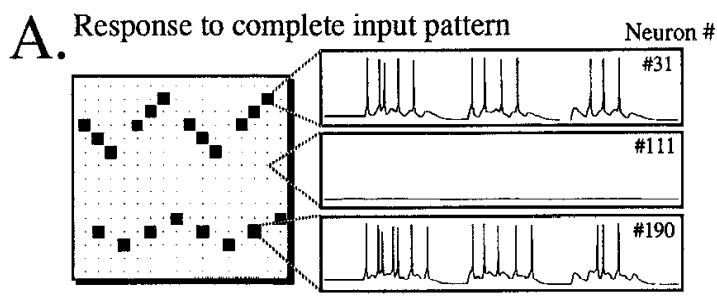

C. Degraded pattern response (after learning with $\mathrm{ACh}$ )

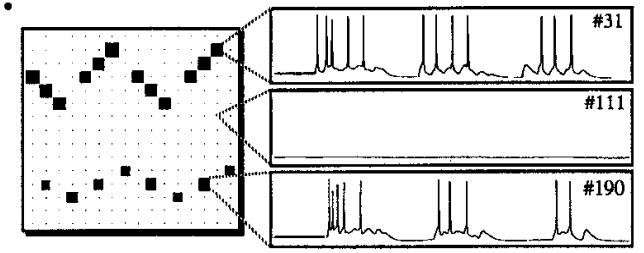

B. Degraded pattern response

(No learning)

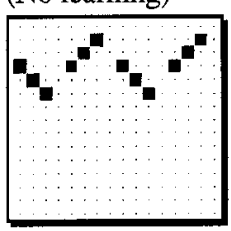

D. Degraded pattern response (after learning without ACh)

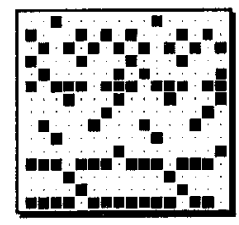

Figure 8. Basic associative memory function within the model. The spiking activity of each of the 240 pyramidal cells is shown in different conditions, with size of black squares representing number of action potentials fired during a $500 \mathrm{msec}$ period. $A$, Response to the complete version of a single stored pattern. Membrane potentials of individual example neurons are shown on the right. $B$, Response to a degraded version of the input pattern (missing eight input lines) before any learning has occurred. $C$, Response to a degraded version of the input pattern after learning in the presence of cholinergic effects. Note that the spread of activity across previously modified intrinsic synapses causes spiking activity in neurons which were elements of the complete learned pattern. $D$, Response to a degraded version of the input pattern after learning without cholinergic suppression of synaptic transmission. Excessive strengthening of intrinsic synapses results in recall of elements of all the patterns stored in the network, preventing discrimination between different patterns (based on figure in Barkai et al., 1994). 
FULL PATTERNS
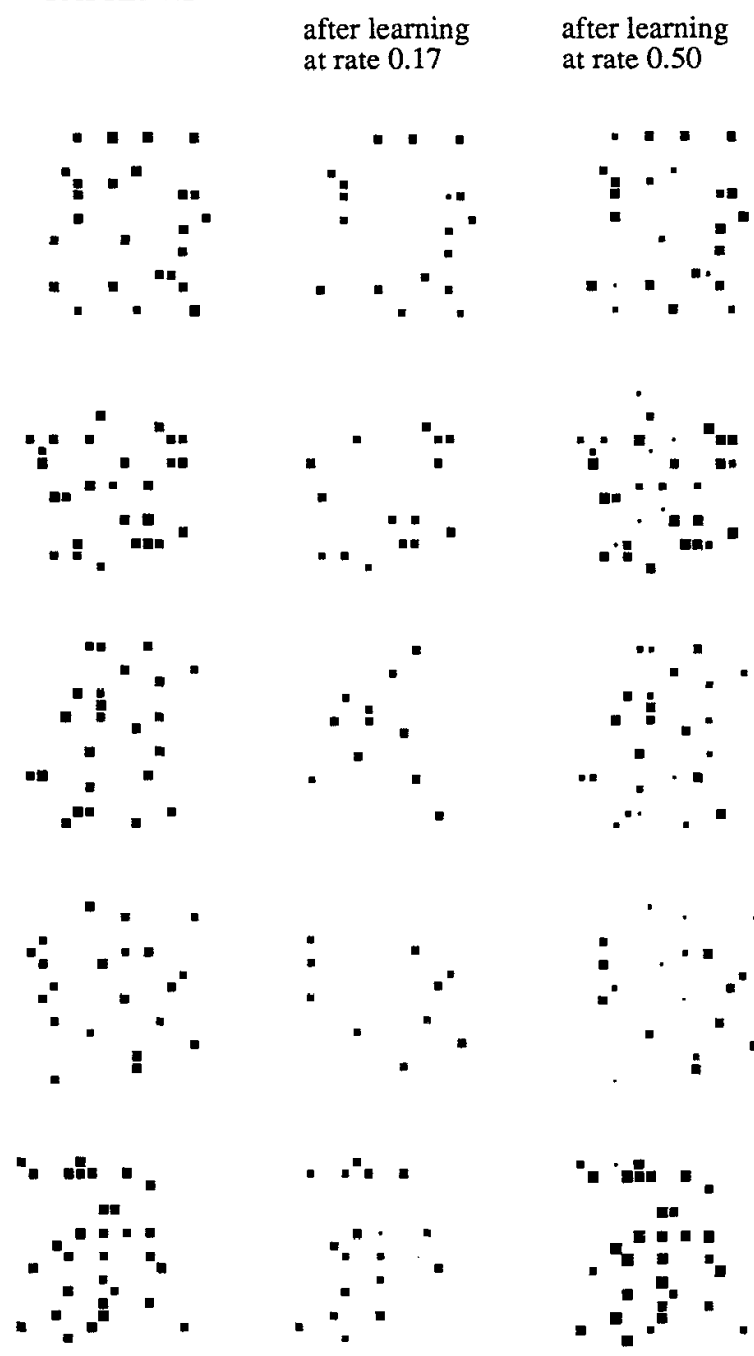

\section{DEGRADED PATTERNS}
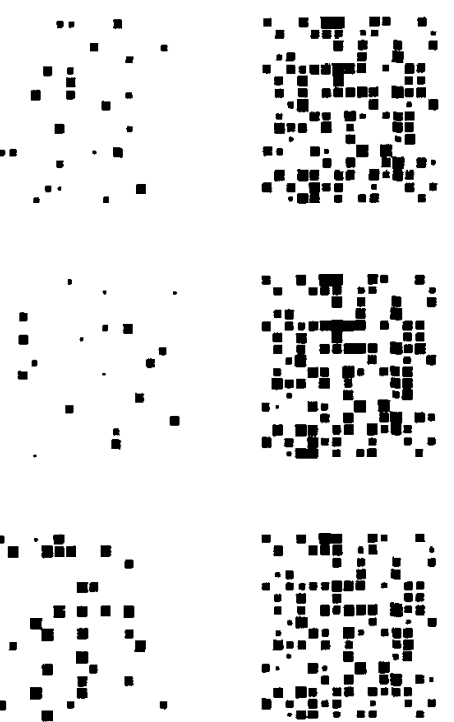

Figure 9. Effects of different learning rates on performance of associative memory function. The first column illustrates the five patterns of activity that were learned by the network. Size of black squares represents the number of spikes fired by each of the 240 simulated piriform cortex pyramidal cells. Each pattern was generated by activating two afferent input fibers, which causes broadly distributed activity in the pyramidal cells. The average percentage of connections between the afferent fibers and the pyramidal cells was $5 \%$. Columns 2-4 represent the activity generated by the network in response to activating only one of the afferent fibers of each pattern. In the second column, responses are shown after learning at a rate which was $17 \%(0.17)$ of the rate that would drive all active connections to their maximal possible weight. After learning at this rate the network was not capable of performing completion of degraded patterns. In the third column, responses to degraded patters after learning at rate which was $50 \%(0.5)$ of the maximal rate are shown. Here, strengthening of intrinsic connections allows completion of missing elements of the degraded pattern (compare with column I). In the fourth column, responses for degraded patterns after learning at rate which was $83 \%(0.83)$ of the maximal rate show spread of activity to a large portion of the network. Responses are very different from the original patterns and are similar to each other, reflecting the loss of discrimination between patterns. which was only 0.17 of the maximal learning rate (as defined in the Materials and Methods section) was used, the network was unable to perform associative memory function, since connections between pyramidal cells were not sufficiently strengthened during the learning mode to allow a spread of activity in the network during the recall mode. Hence, when the partial patterns were presented during recall, the spiking response of the network was incomplete in comparison to the response to the full pattern (conpare the first and second columns in Fig. 9 ). When the learning rate was increased to 0.5 of its maximal value, the network was capable of completing some of the missing inputs, so that the response to the complete and degraded versions resembled each other (compare first and third column). When the learning rate was further increased, the network entered an hyperexcitable state, in which it ceased to discriminate between different patterns. In this state, a degraded version of any of the patterns caused a spread of activity to a large number of pyramidal cells, of which most were not part of the original response (fourth column).

The effect of learning rate on the final synaptic connectivity matrix is demonstrated in Figure 10. Here the size of black squares represents the strength of individual modeled synapses. Increasing the learning rate resulted not only in increased con- nectivity strength between the same neurons, but it also increased the probability of strengthening connections that were not modified at lower learning rates. Figure 10 also describes quantitatively the relation between learning rate and the performance of the network, using the normalized performance measure described in the Materials and Methods section. It is evident that for the period of learning utilized in these simulations only a narrow range of learning rates was suitable for allowing completion specific to individual patterns. Learning rates which were too low resulted in insufficient synaptic modification for associative memory function. Learning rates which were too high resulted in too much interference between the stored patterns.

\section{Effect of adding a depression component}

The narrow range of learning rates which result in good recall (Fig. 10) introduces an interesting question: how can the proper rate of synaptic modification be obtained within the actual neural ensemble? This problem is particularly difficult because of the considerable overlap between groups of neurons activated in the piriform cortex when different odors are presented (Tanabe et al., 1975). This suggests that even if the correct learning rate is applied when an individual memory is stored, these synaptic 
RATE 0.17

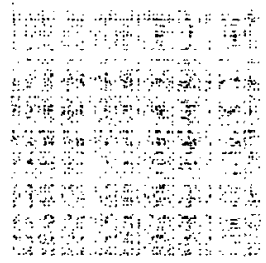

RATE 0.67

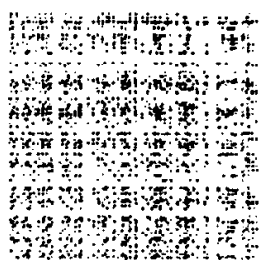

RATE 0.33

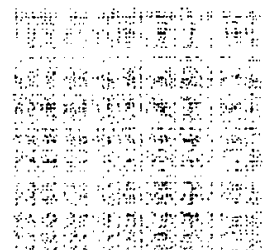

RATE 0.50

and

ar.

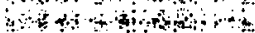
Mathot

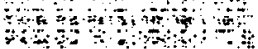

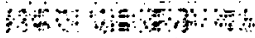

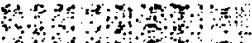

RATE 0.83

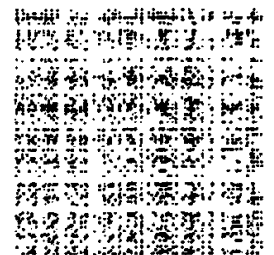

RATE 1.00

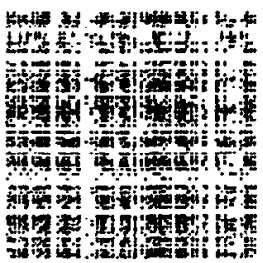

Figure 10. Effect of learning rate on performance of associative memory function. Weight matrices resulting from applying six different learning rates are presented. Size of black squares represents the strength of individual synapses between pyramidal cells (thus, each matrix contains $240 \times$ 240 elements). Note that in this example, increasing the learning rate from 0.17 to 0.5 increases the strength of the same connections. Further increase the learning rate results in addition of previously nonstrengthened weights. Bottom, Graph showing the normalized performance measure as a function of the normalized learning ratc. Effective recall may be obtained only when applying learning rates in the lower range.

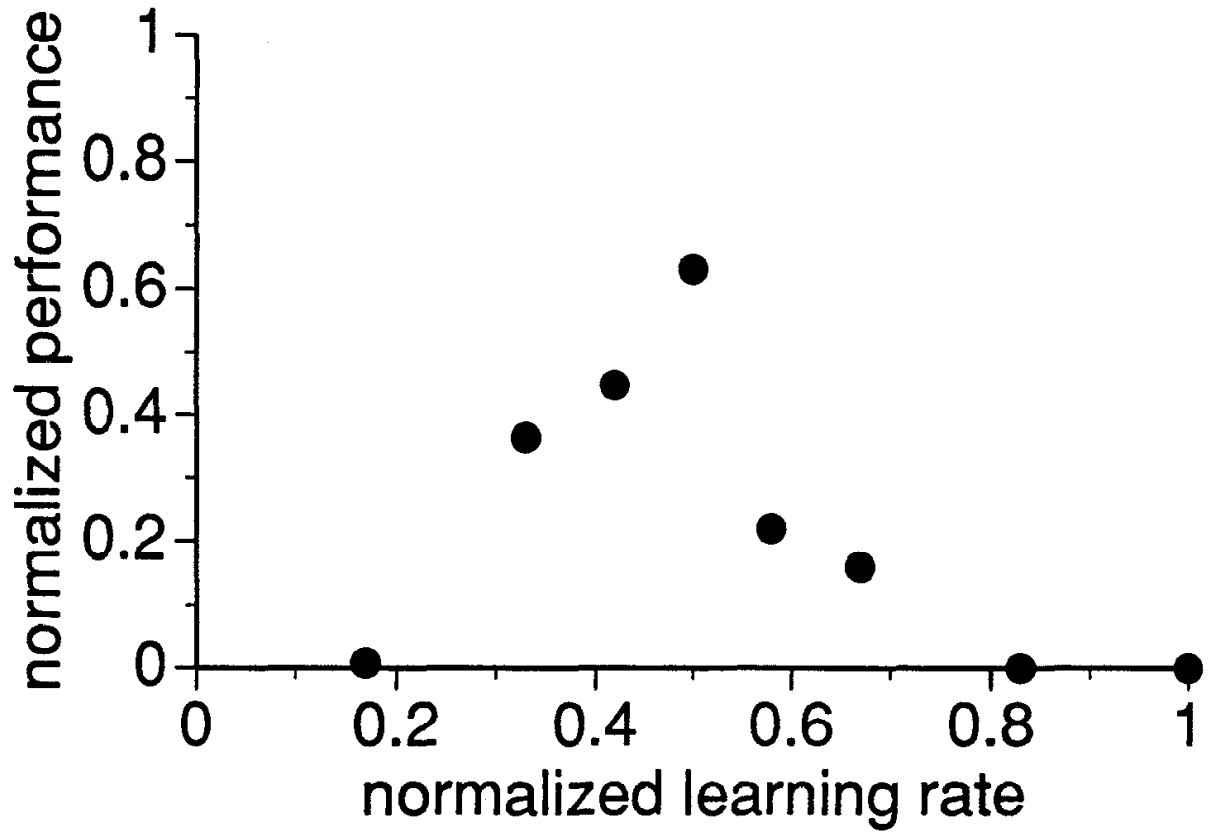

combining a learning rate of 1.0 with different rates of depression during learning (left column), or performing learning with only synaptic enhancement, and allowing depression only during recall (right column). When the depression rate $\gamma$ was set to 0.5 during learning the final synaptic connectivity matrix resembled that obtained when a learning rate of 0.5 was applied with no depression rate (see Fig. 10). Further increasing the depression rate did not result in an obvious change in the final synaptic conncctivity matrix. In sharp contrast, sctting the depression rate to 0 during learning and then increasing it during recall to values of $0.2,0.5$, or 1.0 resulted in a synaptic connectivity matrix which did not have appropriate values for performing pattern synaptic connectivity matrices shown in this figure resulted from The effect of introducing a depression rate into the system on
the synaptic connectivity matrix is shown in Figure 11. The

connections might still be excessively strengthened when additional patterns are presented. strength (Grossberg, 1972; Levy et al., 1990). We examined the possibility that activity-dependent depression in the strength of synaptic connectivity may offer a solution to this problem in the network biophysical simulation. The effect of introducing a depression rate into the system on
the synaptic connectivity matrix is shown in Figure 11 . The 
Depression

\section{during learning}

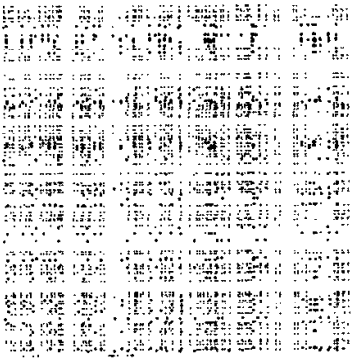

\section{Depression during recall}
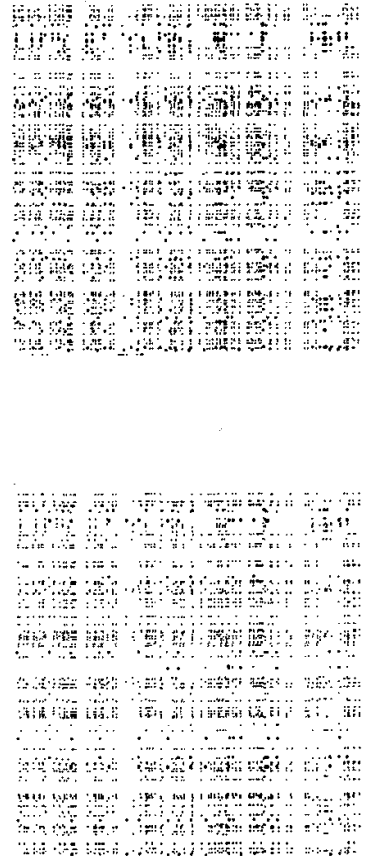

Figure 11. Effect of adding a depression component at different stages of learning or recall on the final synaptic connectivity. Left, This column demonstrates the effect of activating the depression component $\left(-\gamma \mathrm{w}_{\mathrm{ij}}\right)$ during learning (by setting depression rate $\gamma$ to values of $0.2,0.5$, and 1.0 ), when the learning rate was set at 1.0 (maximal learning rate as defined in Materials and Methods). When the depression component $\left(-\gamma \mathrm{w}_{\mathrm{ij}}\right)$ of the learning rule was active during the enhancement it restricted the strengthening of connection to a pattern that resembles those obtained when using a learning rate of 0.5 with no depression (compare results when using depression of 0.5 and 1.0 to using learning rate 0.5 with no depression in Fig. 8). Right, In this column, only enhancement occurred during learning (the depression rate $\gamma$ was set to zero at that time, with learning rate 1.0 as described in Materials and Methods). Depression was applied only during recall, by changing the depression rate $\gamma$ to the values $0.2,0.5$, or 1.0 Note that no enhancement was occurring during recall. Application of depression only during recall greatly weakens synaptic connectivity, preventing effective recall. For example, with a depression rate of 1.0 during recall, the synaptic connections become uniformly small (bottom right). completion. When a depression rate of 0.5 was used during recall, the final synaptic connectivity matrix resembled that obtained when maximal learning rate with no depression was applied, except that the final weights were weaker (right column, middle matrix). When the depression rate was set even higher during recall, the final synaptic connectivity matrix was composed of very weak connections, which did not allow any pattern completion. The different efficacy of applying depression during learning and during recall is illustrated in Figure 12. While introducing depression during recall does not significantly improve associative memory performance, applying the depression rule during learning resulted in a steady improvement of memory, with a similar level of improvement across a range of depression values from 0.4 to 1.0 .

These results suggest that the depression process should take place during learning rather during recall in order to be effective. In other words, the network simulation indicates that a "forgetting" process should occur simultaneously with the learning process, rather than afterwards. This makes the prediction that the depression of synaptic strength should be stronger when cholinergic modulation is present compared to control conditions.

\section{Discussion}

The experiments presented here demonstrate that the cholinergic agonist carbachol enhances long-term potentiation of synaptic strength within the piriform cortex. The accompanying modeling work demonstrates that cholinergic influences on the rate of enhancement and depression of synaptic strength may play an important role in maintaining the stability of associative memory function. In particular, it appears that increased enhancement and depression of synapses should be concurrent with other physiological effects of ACh which may set appropriate dynamics for learning within this region. It appears that the function of the network is best when the cholinergic effects on synaptic modification are present at the same time as the previously described cholinergic suppression of synaptic transmission (Hasselmo and Bower, 1992) and suppression of neuronal adaptation (Barkai and Hasselmo, 1994). 
Figure 12. Recall performance in the model after applying depression during learning and during recall. In the first row three out of five full patterns are represented (same patterns as in Fig. 7). The second row illustrates the completion ability of a network in which learning rate of 1.0 was combined with depression rate of 0.6 during learning. The responses to three degraded patterns are shown (degraded patterns are the same as in Fig. 7, column 2). The third row shows that applying a depression rate of 0.5 during recall after training with learning rate of 1.0 does not allow completion of the patterns. Bottom, Graph showing the normalized performance measure during recall as a function of the depression rate during learning (solid circles) and during recall (open circles). A learning rate of 1.0 was applied. No depression rate is efficient when applied after learning. In contrast, when depression is applied during learning, all depression rates with values of 0.4 or more are efficient in improving recall performance considerably. These results suggest that synaptic depression should be enhanced at the same time as synaptic strengthening.
FULL PATTERNS
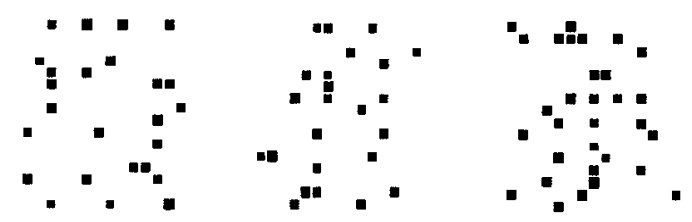

DEGRADED

PATTERNS,

DEPRESSION

DURING

LEARNING (0.6)
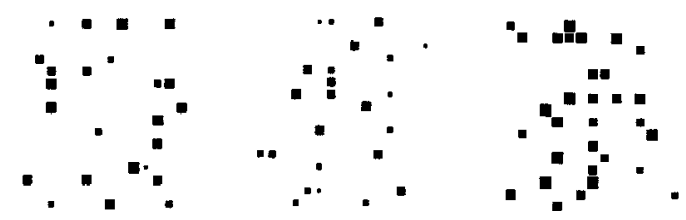

DEGRADED
PATTERNS,
DEPRESSION
DURING
RECALL $(0.5)$
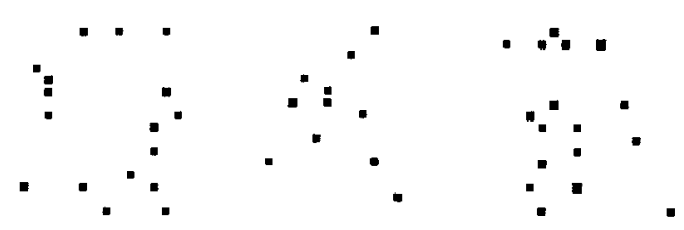

depression during leaming

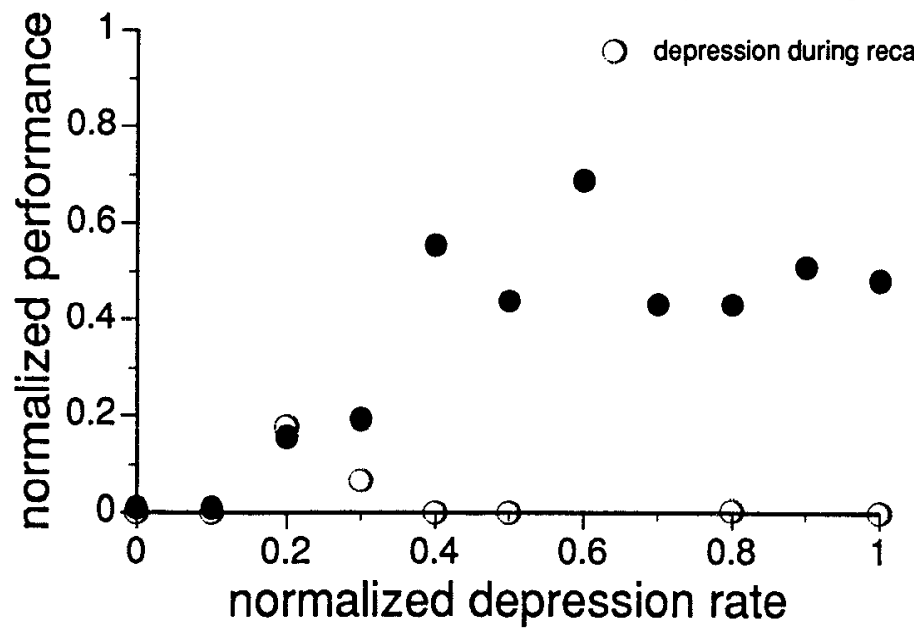

\section{Long-term potentiation in the piriform cortex}

Long-term potentiation has been demonstrated previously in the piriform cortex, using patterned trains of stimulation. Two different groups demonstrated long-term potentiation induced by bursts of four pulses each (at $100 \mathrm{~Hz}$ ) presented every $200 \mathrm{msec}$ ( $5 \mathrm{~Hz}$ ) (Jung et al., 1990; Kanter and I laberly, 1990). This longterm potentiation can be blocked by APV, suggesting it is dependent upon activation of NMDA channels, presumably because the high frequency stimulation causes sufficient postsynaptic depolarization due to temporal summation of synaptic inputs. In previous work (Jung et al., 1990), the probability of LTP induction increased when extracellular $\mathrm{Mg}^{2+}$ concentration was reduced to $50 \mu \mathrm{M}$, thereby allowing activation of the NMDA channel at resting potential. In our study, high frequency stimulation was not used, and postsynaptic depolarizing current injection only moderately enhanced the synaptic modification, possibly due to insufficient spread of depolarization from the soma into dendritic regions. The increase in amplitude of LTP in the presence of carbachol may be due to cholinergic enhancement of NMDA currents such as that described in the hippocampus (Markram and Segal, 1990). The increase might also be aided by cholinergic suppression of potassium currents causing membrane potential depolarization. Since these effects would be local to the postsynaptic membrane, they could be a stronger effect than the activation due to intracellular current injection at the soma. In our experiments, the increase in amplitude of the EPSP following repetitive stimulation was gradual. This finding has been reported previously for the piriform cortex (Jung et al., 1990), and has also been noted for hippocampal LTP (Jaffe and Johnston, 1990; see Figs. 5 and 6).

Long-term potentiation in the piriform cortex has been demonstrated in experiments testing the learning of new olfactory information (Roman et al., 1987). In particular, it was proposed that neuromodulatory influences might be necessary to allow LTP in the context of particular behavioral tasks. However, that test of long-term potentiation focused on modification of the afferent input to the piriform cortex, while magnitude of afferent fiber synaptic modification was not tested in this experiment. Considerable previous modeling has focused on the role of synaptic modification of afferent fiber synapses in the self-organized heirarchical categorization of olfactory information (Ambros-Ingerson et al., 1990). This work is not incompatible with the focus 
in the current article on associative memory function. In fact, cholinergic suppression of synaptic transmission within the piriform cortex may allow self-organization of the afferent fibers to proceed without interference from the spread of activity at intrinsic fiber synapses (Hasselmo, 1994b). Further data from the piriform cortex suggests that long-term potentiation of inhibitory feedback synapses may also occur (Stripling et al., 1988).

\section{Cholinergic modulation of long-term potentiation}

The results presented here on cholinergic modulation of LTP in the piriform cortex support previous work showing cholinergic enhancement of long-term potentiation in the dentate gyrus (Burgard and Sarvey, 1989), hippocampal region CA1 (Blitzer et al., 1991; Huerta and Lisman, 1994). Other studies have shown that LTP induction is suppressed in CA1 cells when muscarinic antagonists are applied (Hirotsu et al., 1989), while application of a cholinesterase inhibitor enhances LTP (Tanaka et al., 1989), suggesting that tonic levels of ACh in the slice may influence the induction of LTP. In addition, the cholinergic enhancement of LTP may be closely linked to the cholinergic induction of theta rhythm oscillations (Huerta and Lisman, 1994). Recently, long-term potentiation of synaptic potentials in hippocampal region $\mathrm{CA} 1$ has been reported to occur in the presence of submicromolar doses of carbachol without requiring any stimulation (Auerbach and Segal, 1994). However, this effect appeared only at concentrations of carbachol smaller than $5 \mu \mathrm{M}$. Cholinergic enhancement of long-term potentiation has also been demonstrated in slice preparations of the primary visual cortex (Brocher et al., 1992). Just as cholinergic enhancement of LTP has been shown in a variety of cortical structures, other cholinergic effects such as the suppression of synaptic transmission and neuronal adaptation have been described in a range of cortical structures (see Hasselmo and Bower, 1993; Hasselmo, 1994b, for review). This supports the notion that the effects described here for the piriform cortex may ultimately apply as a general principle to the function of all cortical structures. Cholinergic enhancement of LTP may need to be coupled with cholinergic suppression of synaptic transmission and neuronal adaptation for the proper dynamics of learning in structures as diverse as the hippocampus, piriform cortex, and primary visual cortex.

\section{Long-term depression and the learning of stable memory sicates}

The significance of the cholinergic modulation of synaptic modification was here examined using a realistic biophysical network simulation. We tested the hypothesis that the rate of synaptic modification must be regulated to maintain the capacity of the storage system. Excessive strengthening of synaptic connections within the cortex can result in a loss of specificity of response to specific input patterns, or even a exponential growth in cortical activity resembling seizure activity. The possibility of such explosive breakdown in function is of particular interest for the piriform cortex, which has been shown to be highly prone to induction of seizure activity (Piredda and Galc 1985, 1986; McIntyre and Wong, 1986; Haberly and Sutula, 1992). Using a previously developed hiophysical simulation (Barkai and Hasselmo, 1994; Barkai et al., 1994; Hasselmo et al., 1994) we have found that increases in learning rate only enhance storage capacity up to a certain point. Higher rates of modification can cause interference between different stored patterns, reducing the performance of the network and finally causing activity resembling a seizure when any pattern is presented.

The problem of excessive synaptic modification can be offset by incorporating activity-dependent rules for synaptic depression in the simulation, thereby maintaining storage capacity and preventing the problem of an excessive rate of increase in synaptic strength. However, the activity-dependent synaptic depression should be selectively present at the time when synaptic enhancement is occurring, but not during recall. Thus, the model has generated a prediction which can be used to experimentally test the validity of the model. Recent research has provided information on possible mechanisms for long-term depression (Mulkey et al., 1993; Bolshavok and Sigelbaum, 1994). Further studies are necessary to explore whether cholinergic agonists enhance long-term depression in slice preparations of the rat piriform cortex.

In conclusion, we propose that by simultaneously causing two seemingly opposite effects - the enhancement of long-term potentiation and the enhancement of long-term depression- $\mathrm{ACh}$ may set the proper dynamics for maximizing the learning and storage capacity of the piriform cortex.

\section{References}

Aigner TG, Walker DL, Mishkin M (1991) Comparison of the effects of scopolamine administrated before and after acquisition in a test of visual recognition memory in monkeys. Behav Neural Biol 55:6167.

Ambros-Ingerson J, Granger J, Lynch G (1990) Simulation of paleocortex performs heirarchical clustering. Science 247:1344-1348.

Artola A, Singer W (1987) Long-term potentiation and NMDA receptors in rat visual cortex. Nature 330:649-652.

Auerbach JM, Segal M (1994) A novel cholinergic induction of longterm potentiation in rat hippocampus. J Neurophysiol 72:2034-2040.

Barkai E, Hasselmo ME (1994) Modulation of the input/output function of rat piriform cortex pyramidal cells. J Neurophysiol 72:644 658.

Barkai E, Bergman R, Horwitz G, Hasselmo ME (1994) Modulation of associative memory function in a biophysical simulation of rat piriform cortex. J Neurophysiol 72:659-677.

Bear MB, Press WA, Connors BW (1992) Long-term potentiation in slices of kitten visual cortex and the effects of NMDA receptor blockade. J Neurophysiol 67:841-851.

Bliss TVP, Collingridge GL (1993) A synaptic model of memory: longterm potentiation in the hippocampus. Nature 361:31-40.

Blitzer RD, Gil O, Landau EM (1990) Cholinergic stimulation enhances long-term potentiation in the CA1 region of rat hippocampus. Neurosci Lett 119:207-210.

Bolhsakov VY, Siegelbaum SA (1994) Postsynaptic expression of hippocampal long-term depression. Science 264:1148-1151.

Brocher S, Artola A, Singer W (1992) Agonists of cholinergic noradrenergic receptors facilitate synergistically the induction of long-term potentiation in slices of rat visual cortex. Brain Res 573:27-36.

Burgard EC, Sarvey JM (1990) Muscarinic receptor activation facilitates the induction of long-term potentiation (LTP) in the rat dentate gyrus. Neurosci Lett 116:34-39.

Connors BW, Malenka RC. Silva LR (1988) Two inhibitory postsynaptic potentials and GABAa and GABAb receptor-mediated responses in neocortex of rat and cat. J Physiol (Lond) 406:443-468.

Constant A, Sim JA (1987) Calcium-dependent potassium conductance in guinea-pig olfactory cortex neurons in vitro. J Physiol (Lond) 387: 173-194.

Dudek S, Bear MF (1993) Bidirectional long-term modification of synaptic effectiveness in the adult and immature hippocampus $J$ Neurosci 13:2910-2918.

Feig S, Lipton P (1993) Pairing the cholinergic agonist carbachol with patterned schaffer collateral stimulation initiates protein synthesis in hippocampal C.A1 pyramidal cell dendrites via a muscarinic, NMDAdependent mechanism J Neurosci 13:1010-1021.

Grossberg S (1972) Some networks that can learn, remember and re- 
produce any number of complicated space-time patterns. II. Stud Appl Math 49:135-166.

Haberly LB (1985) Neuronal circuitry in olfactory cortex: anatomy and functional implications. Chem Senses 10:219-238.

Haberly LB, Bower JM (1989) Olfactory cortex: model circuit for study of associative memory? Trends Neurosci 12:28-264.

Haberly LB, Sutula TP (1992) Neuronal processes that underlie expression of kindled epileptiform events in the piriform cortex in vivo. J Neurosci 12:2211-2224

Hagan JJ, Morris RGM (1989) The cholinergic hypothesis of memory: a review of animal experiments. In: Psychopharmacology of the aging nervous system (Iversen LL, Snyder SH, eds), pp 237-324. New York: Plenum.

Hagan JJ, Jansen JHM, Broekkamp CLE (1987) Blockade of spatial learning by the M1 muscarinic antagonist pirenzepine. PsychopharInacology 93:470-476.

Hasselmo ME (1993) Acetylcholine and learning in a cortical associative memory. Neural Comp 5:32-44

Hasselmo ME (1994) Runaway synaptic modification in models of cortex: implications for Alzheimer's disease. Neural Networks 7:1340.

Hasselmo ME (1995) Neuromodulation and cortical function: modeling the physiological basis of behavior. Behav Brain Res 67:1-27.

Hasselmo ME, Bower JM (1992) Cholinergic suppression of specific to intrinsic not afferent fibers in rat piriform (olfactory) cortex. J Neurophysiol 67:1222-1229.

Hasselmo ME, Bower JM (1993) Acetylcholine and memory. Trends Neurosci 16:218-222.

Hasselmo ME, Anderson BP, Bower JM (1992) Cholinergic modulation of cortical associative memory function. J Neurophysiol 67: $1230-1246$

Hasselmo ME, Barkai E, Horwitz G, Bergman RE (1994) Modulation of neuronal adaptation and cortical associative memory function. In: Computation and neural systems (Eeckman F, Bower JM, eds). Norwell, MA: Kluwer.

Hawkins RD, Kandel ER, Siegelbaum SA (1993) Learning to modulate transmitter release: themes and variations in synaptic plasticity. Annu Rev Ncurosei 16:625-665.

Hirotsu I, Hori N, Katsuda N, Ishihara T (1989) Effect of an anticholinergic drug on long-term potentiation in rat hippocampal slices. Brain Res 482:194-197.

Huerta PT, Lisman JE (1994) Heightened synaptic plasticity of hippocampal CAl neurons during a cholinergically induced rhythmic state. Nature 364:723-725.

Hunter AJ, Murray TK (1989) Cholinergic mechanisms in a simple test of olfactory learning in the rat. Psychopharmacology 99:270 275.

Jaffe D, Johnston D (1990) Induction of long-term potentiation at hippocampal mossy-fiber synapses follows a hebbian rule. J Neurophysiol 64:948-960.

Jung MW, Larson L, Lynch G (1990) Long-term potentiation of monosynaptic EPSPs in rat piriform cortex in vitro. Synapse 6:279-283.

Kanter ED, Haberly LB (1990) NMDA-dependent induction of longterm potentiation in afferent and association fiber systems of piriform cortex in vitro. Brain Res 525:175-179.

Kanter ED, Haberly LB (1993) Associative long-term potentiation cortex slices requires $\mathrm{GABA}_{\mathrm{A}}$ blockade. J Neurosei 13:2477-2482.

Levy WB, Colbert CM, Desmond NL (1990) Elemental adaptive pro- cesses of neurons and synapses: a statistical/computational perspective. In: Neuroscience and connectionist thcory (Gluck MA, Rumelhart DE, eds), pp 187-236. Hillsdale, NJ: Erlbaum.

Madison DV, Lancaster B, Nicoll RA (1987) Voltage clamp analysis of cholinergic action in the hippocampus. J Neurosci 7:733-741.

Markram H, Segal M (1990) Long-lasting facilitation of excitatory postsynaptic potentials in rat hippocampus by acetylcholine. J Physiol (Lond) 427:381-393.

McIntyre DC, Wong RKS (1986) Cellular and synaptic properties of amygdala-kindled pyriform cortex in vitro. J Neuorphysiol 55:12951307

Mulkey RM, Herron CE, Malenka RC (1993) An essential role for protein phosphatases in hippocampal long-term depression. Science 261:1051-1054

Piredda S, Gale K (1985) A crucial epileptogenic site in the deep prepiriform cortex. Nature 317:623-625.

Piredda S, Gale K (1986) Role of excitatory amino acid transmission in the genesis of seizures elicited from the deep prepiriform cortex. Brain Res 377:205-210.

Rall W (1989) Cable theory for dendritic neurons. In: Methods in neuronal modeling: from synapses to networks (Koch C, Segev I, eds), pp 9-62. Cambridge, MA: MIT Press.

Roman F, Stabuli U, Lynch G (1987) Evidence for synaptic potentiation in a cortical network during learning. Brain Res 418:221 226.

Soffie M, Lamberty Y (1988) Scopolamine effects on juvenile conspecific recognition in rats: possible interaction with olfactory sensitivity. Behav Proc 17:181-190.

Stripling JS, Patneau DK, Gramlich CA (1988) Selective long-term potentiation in the pyriform cortex. Brain Res 441:281-291.

Sutherland RJ, Wishaw IQ, Regehr JC (1982) Cholinergic receptor blockade impairs spatial localization by use of distal cues in the rat. J Comp Physiol Psychol 96:563-573.

Tanabe Y, lino M, Takagi SF (1975) discrimination of odors on olfactory bulb pyriform-amygdaloid areas and orbitofrontal cortex of the monkey. J Neurophysiol 38:1284-1296.

Tanaka Y, Sakurai M, Hayashi S (1989) Effect of scopolamine and HP 029, a cholinergic inhibitor, on long-term potentiation in hippocampal slices of the guinea pig. Neurosci Lett 98:179-183.

Tang AC, Hasselmo ME (1994) Selective suppression of intrinsic but not afferent fiber synaptic transmission by baclofen in the piriform (olfactory) cortex. Brain Res 659:75-81.

Tseng GF, Haberly LB (1988) Characterization of synaptically mediated fast and slow inhibitory processes in piriform cortex in an in vitro slice preparation. J Neurophysiol 59:1352-1376.

Tseng GF, Haberly LB (1989) Deep neurons in piriform cortex. II. Membrane properties that underlie unusual synaptic responses. J Neurophysiol $62: 386-400$.

Wigstrom H, Gustafsson B, Huang YY, Abraham WC (1986) Hippocampal long-term potentiation is induced by pairing single afferent volleys with intracellularly injected depolarizing current pulses. Acta Physiol Scand 126:317-319.

Wilson MA, Bower JM (1989) The simulation of large-scale neuronal networks. In: Methods in neuronal modeling: from synapses to networks (Koch C, Segev I, eds), pp 291-334. Cambridge, MA: MIT Press.

Wilson MA, Bower JM (1992) Cortical oscillations and temporal interactions in a computer simulation of piriform cortex. I Neurophysiol 67:981-995. 